\title{
Quantificação de raízes metabolicamente ativas de cana-de-açúcar
}

\author{
Carlos Eduardo Faroni( ${ }^{(1)}$ e Paulo Cesar Ocheuze Trivelin ${ }^{(2)}$
}

\begin{abstract}
(1)Escola Superior de Agricultura Luiz de Queiroz, Av. Pádua Dias, no 11, Caixa Postal 9, CEP 13418-900 Piracicaba, SP. E-mail: cefaroni@esalq.usp.br (2)Centro de Energia Nuclear na Agricultura, Laboratório de Isótopos Estáveis, Av. Centenário, ํo 303, Caixa Postal 96, CEP 13400-970 Piracicaba, SP. E-mail: pcotrive@cena.usp.br
\end{abstract}

\begin{abstract}
Resumo - O objetivo deste trabalho foi desenvolver um método para determinar a distribuição e o desenvolvimento de raízes metabolicamente ativas de cana-de-açúcar no solo, por meio da técnica da diluição do isótopo ${ }^{15} \mathrm{~N}$. O delineamento experimental foi em blocos subdivididos no tempo. A uréia foi o meio de fornecimento do traçador ${ }^{15} \mathrm{~N}$, a partir de solução aplicada às folhas das plantas. Depois da colheita da parte aérea, foram abertas trincheiras, e as amostras de solo + raízes foram colhidas por meio de monólito. O método da diluição isotópica com ${ }^{15} \mathrm{~N}$ possibilitou avaliar a massa de raízes com metabolismo ativo e sua distribuição no solo. Houve maior distribuição porcentual das raízes metabolicamente ativas em profundidade do que na superfície do perfil, que correspondeu, respectivamente, a 31\% na camada de 0,6-0,8 m e 23\% na camada de 0,0-0,2 m. Além disso, o método possibilitou determinar raízes metabolicamente ativas que permaneceram no solo depois do peneiramento, que foi de 35\%, o que evidencia a importância da quantificação dessas raízes.
\end{abstract}

Termos para indexação: sistema radicular, isótopo estável, nitrogênio, perfil de solo.

\section{Quantification of sugarcane active metabolism roots}

\begin{abstract}
The objective of this work was to evaluate a method to determine sugarcane roots with active metabolism and its distribution and growth in the soil profile, by using isotopic dilution technique with ${ }^{15} \mathrm{~N}$. The experimental design was in randomized blocks, the split plot was considered in relation to time. The ${ }^{15} \mathrm{~N}$ tracer was applied in the leaves of the plants as urea solution. After the harvest of the above ground part of sugarcane plants, trenches were opened and the soil + roots samples were taken by monolite. The isotopic dilution method with ${ }^{15} \mathrm{~N}$ allowed evaluating active root mass and the root distribution in the soil. There is a larger percentual distribution of the roots with active metabolism in depth than in the surface of the profile, which stands for, respectively, $31 \%$ in the layer of $0.6-0.8 \mathrm{~m}$ and $23 \%$ in the layer of $0.0-0.2 \mathrm{~m}$. The method also made possible to determine the roots with active metabolism that remained in the soil after sieve, that was 35\%, showing the importance of determining these roots.
\end{abstract}

Index terms: root system, stable isotope, nitrogen, soil profile.

\section{Introdução}

Um dos fatores de maior importância na relação planta-água-solo é a arquitetura e distribuição do sistema radicular das plantas, bem como sua dinâmica de crescimento (Vasconcelos, 2002). O conhecimento do sistema radicular da cana-de-açúcar permite a utilização adequada das técnicas agronômicas, tais como: espaçamento, local de aplicação dos fertilizantes, operações de cultivo, drenagem dos solos e sistemas de irrigação, controle da erosão, uso de culturas intercalares entre outras (Casagrande, 1991).

O estudo do sistema radicular tem sido relegado devido às variabilidades de condições físicas, químicas e biológicas do solo, as quais influenciam a distribuição das raízes. Tais variabilidades podem levar a resultados não representativos do desenvolvimento normal do sistema radicular das plantas (Vasconcelos et al., 2003). O desenvolvimento do sistema radicular de culturas perenes e semi-perenes, como a cana-de-açúcar, apresenta um agravante, no que se refere à renovação de raízes entre ciclos, ou no mesmo ciclo, tornando-se necessário a identificação de raízes vivas ou metabolicamente ativas em uma massa total amostrada (Faroni, 2004).

Depois do corte da cana-planta, o sistema radicular antigo mantém-se em atividade por algum tempo e, durante esse período, é substituído pelas raízes dos novos perfilhos da soqueira, sendo esse processo lento e gradual. As raízes da soqueira são mais superficiais que 
as da cana-planta pelo fato de os perfilhos das soqueiras brotarem mais próximo da superfície que os da planta. Pelo mesmo fato, quanto maior o número de cortes, mais superficial o sistema radicular das soqueiras (Bacchi, 1983).

O desenvolvimento do sistema radicular é típico a cada espécie, havendo crescimento acumulativo do sistema radicular durante os ciclos da cultura, da cana-planta para as socas sucessivas; a morte ou a renovação do sistema radicular não é causada pela colheita da cultura e sim pela deficiência hídrica, independentemente da fase de desenvolvimento (Aguiar, 1978; Vasconcelos, 2002).

O sistema radicular da cana-de-açúcar (rizomas e raízes) é essencial para a rebrota das soqueiras, uma vez que cumpre o papel de reserva orgânica energética e nutricional (Camargo, 1989; Malavolta, 1994; Trivelin et al., 2002). Ao mesmo tempo em que ocorre a brotação das socas, um novo sistema radicular é formado, e algumas raízes vivas são importantes para alimentar os rebentos na fase inicial de desenvolvimento (Casagrande, 1991).

Segundo Russel \& Fillery (1996), poucos estudos sobre raízes têm sido desenvolvidos e os procedimentos adotados na avaliação do $\mathrm{N}$ de sistema radicular raramente recuperam as raízes finas e as rizodeposições. Com o uso do marcador isotópico ${ }^{15} \mathrm{~N}$, via aplicação foliar, o estudo do sistema radicular da cana-de-açúcar pode ser realizado, uma vez que o ${ }^{15} \mathrm{~N}$ é translocado até a parte subterrânea da planta (Trivelin et al., 1988). O fornecimento foliar de fontes nitrogenadas marcadas com ${ }^{15} \mathrm{~N}$ em solução diluída, em princípio, não causa distúrbios à planta, na qual o material marcado distribui-se uniformemente, podendo ser utilizado para determinar o $\mathrm{N}$ no sistema radicular (Jansen \& Bruinsma, 1989).

McNeill et al. (1997), estudando o N no sistema solo-planta nas espécies de pastagem trevo (Trifolium subterraneum L.) e serradella (Ornithopus compressus L.), consideraram adequado o método de fornecimento de ${ }^{15} \mathrm{~N}$ por meio da aplicação foliar com uréia marcada. Mesmo em soluções de baixas concentrações, esse método foi suficiente para marcar as raízes das plantas e traçar a dinâmica do elemento no sistema.

O objetivo deste trabalho foi desenvolver um método para determinar a distribuição e o desenvolvimento de raízes metabolicamente ativas de cana-de-açúcar no solo, por meio da técnica da diluição do isótopo ${ }^{15} \mathrm{~N}$.

\section{Material e Métodos}

A área experimental localizou-se em talhão comercial de cana-de-açúcar pertencente ao Grupo Cosan S/A - Unidade Costa Pinto, no Município de Piracicaba, SP. A variedade de cana-de-açúcar utilizada foi a RB85 5156, de alta precocidade em maturação e bom vigor de rebrota. O solo da área experimental foi classificado como Latossolo Vermelho distrófico (Embrapa, 1999). As amostragens de raízes foram realizadas em 19/1 (256 dias após o corte - dac), 10/3 (307 dac), 11/5 (369 dac) e 22/6 (411 dac) de 2004, em uma segunda rebrota da cultura.

O delineamento experimental foi o de blocos subdivididos no tempo, divididos em parcelas, com quatro repetições por época. Os blocos, constituídos de três segmentos contíguos de linhas de cana-de-açúcar de $2 \mathrm{~m}$ de comprimento e distante três linhas um do outro, foram distribuídos transversalmente, no sentido da linha de plantio de cana-de-açúcar, para efeito de controle local, correspondendo, cada bloco, a uma trincheira. As parcelas, dentro de cada bloco, representaram locais de amostragem, formados pela intersecção de uma profundidade $(0,0-0,2,0,2-0,4,0,4-0,6$ ou $0,6-0,8 \mathrm{~m}) \mathrm{e}$ uma distância da linha de plantio (na linha, 0,14-0,42 m ou $0,42-0,70 \mathrm{~m}$ da linha), num total de 12 parcelas por bloco.

A fonte utilizada como marcador isotópico foi a uréia, com abundância de $25 \%$ em átomos de ${ }^{15} \mathrm{~N}$, fornecida em $10 \mathrm{~mL}$ de solução, com concentração de 31\% $(\mathrm{m} / \mathrm{v})$, às plantas de segmento de linha de $2 \mathrm{~m}$ de comprimento, em cada bloco. A aplicação da solução de uréia foi feita por pulverização foliar, sendo a colheita do material realizada após 96 horas da aplicação. Antes das pulverizações, cobriu-se a superfície do solo com lona de plástico, dos dois lados do segmento de linha a ser pulverizado, a fim de evitar possível contato da solução com o solo, por deriva ou escorrimento. A lona de plástico permaneceu cobrindo a superfície do solo até a colheita.

Na coleta das amostras de solo e raízes, foi usado o método do monólito, por permitir estimar a quantidade total de raízes com exatidão, apesar de apresentar baixa precisão e ser de difícil execução (Köpke, 1981). Para a coleta dos monólitos, foi confeccionado um amostrador em aço inox com as dimensões de $0,28 \mathrm{~m}$ de comprimento, 0,10 m de largura e 0,20 m de profundidade, com um volume de coleta de 5,6 $\mathrm{dm}^{3}$. Essas dimensões foram definidas de acordo com o espaçamento 
da cultura e das profundidades de amostragem. Os monólitos foram, então, obtidos na parede de trincheiras abertas transversalmente à linha de cana, no centro das parcelas marcadas com ${ }^{15} \mathrm{~N}$. As trincheiras tinham as dimensões de 1,0 m na linha e 1,4 m de entrelinha a entrelinha. As amostras foram colhidas nas profundidades de $0,0-0,2,0,2-0,4,0,4-0,6$ e $0,6-0,8 \mathrm{~m}$, na projeção da linha da cultura e nas laterais dessas amostras, distantes 0,14-0,42 m e 0,42-0,70 m da linha.

As amostras de solo contendo raízes foram separadas em raízes totais, solo contendo resíduo de raízes e uma amostra de raízes aparentemente vivas, por profundidade de coleta. Depois da coleta dos monólitos, as raízes foram separadas do solo por peneiramento (malha $2 \mathrm{~mm}$ ), obtendo-se amostras de raízes totais. Nas amostras de raízes totais e raízes aparentemente vivas, o solo aderido foi removido por meio de lavagem em água corrente. As amostras de raízes foram secadas em estufa com circulação forçada de ar, a $65^{\circ} \mathrm{C}$, até atingirem massa constante. Após a secagem, as amostras foram pesadas para quantificação de massa de matéria seca e estimativa da distribuição do sistema radicular no perfil do solo. As amostras de raízes, depois de pesadas, foram moídas em moinho Wiley, subamostradas e o teor de $\mathrm{N}$ e a abundância de ${ }^{15} \mathrm{~N}$ foram determinados em um espectrômetro de massas, modelo ANCA-SL
(Barrie \& Prosser, 1996). As amostras de solo do monólito foram passadas em moinho de bola para uma melhor homogeneização antes das determinações de $\mathrm{N}$ total e de abundância de ${ }^{15} \mathrm{~N}$.

Desde a superfície, e por todo o perfil do solo onde foram coletados os monólitos, para cada profundidade de amostragem e na projeção da linha da cultura, foram separadas amostras de raízes consideradas visualmente vivas (ativas). Essas amostras foram consideradas padrões na determinação, por diluição isotópica, de raízes vivas do total de raízes amostradas. Na utilização dessas amostras de raízes como padrões, adotou-se, segundo Jansen \& Bruinsma (1989), a suposição da uniformidade de distribuição do marcador isotópico na planta.

No cálculo do material de raízes metabolicamente ativas de cada amostra, foram utilizadas as abundâncias isotópicas, as massas e os teores de $\mathrm{N}$ das amostras, além das abundâncias e dos teores de $\mathrm{N}$ dos padrões de raízes vivas e as abundâncias do solo natural (Tabelas 1 e 2), segundo McNeill et al. (1997) e Trivelin et al. (2002).

A porcentagem de $\mathrm{N}$ derivada de raízes metabolicamente ativas (\%NaRMA) foi obtida pela equação: $\%$ NaRMA $=\left[\left(\%{ }^{15} \mathrm{~N}_{\text {amostra }}-\%^{15} \mathrm{~N}_{\text {solo }}\right) /\left(\%{ }^{15} \mathrm{~N}_{\text {raiz m.a. }}-\right.\right.$ $\left.\left.\%{ }^{15} \mathrm{~N}_{\text {solo }}\right)\right] \times 10^{2}$ em que: \% ${ }^{15} \mathrm{~N}_{\text {amostra }}$ é a abundância em porcentagem de átomos de ${ }^{15} \mathrm{~N}$ na amostra; $\%{ }^{15} \mathrm{~N}_{\text {solo }}$ é a abundância em

Tabela 1. Abundância em ${ }^{15} \mathrm{~N}\left(\%{ }^{15} \mathrm{~N}\right)$ e porcentagem de $\mathrm{N}$ dos compartimentos estudados, por profundidade, nas quatro épocas de amostragem ${ }^{(1)}$.

\begin{tabular}{|c|c|c|c|c|c|c|c|c|}
\hline \multirow[t]{2}{*}{ Profundidade $(\mathrm{m})$} & \multicolumn{2}{|c|}{ Jan./256 dac } & \multicolumn{2}{|c|}{ Mar./307 dac } & \multicolumn{2}{|c|}{ Maio/369 dac } & \multicolumn{2}{|c|}{ Jun./411 dac } \\
\hline & $\%{ }^{15} \mathrm{~N}$ & $\mathrm{~N}(\%)$ & $\%{ }^{15} \mathrm{~N}$ & $\mathrm{~N}(\%)$ & $\%{ }^{15} \mathrm{~N}$ & $\mathrm{~N}(\%)$ & $\%{ }^{15} \mathrm{~N}$ & $\mathrm{~N}(\%)$ \\
\hline & \multicolumn{8}{|c|}{ Padrão solo } \\
\hline $0,0-0,2$ & 0,371 & 0,04 & 0,371 & 0,04 & 0,371 & 0,04 & 0,371 & 0,04 \\
\hline $0,2-0,4$ & 0,370 & 0,03 & 0,370 & 0,03 & 0,370 & 0,03 & 0,370 & 0,03 \\
\hline $0,4-0,6$ & 0,370 & 0,02 & 0,370 & 0,02 & 0,370 & 0,02 & 0,370 & 0,02 \\
\hline $0,6-0,8$ & 0,369 & 0,02 & 0,369 & 0,02 & 0,369 & 0,02 & 0,369 & 0,02 \\
\hline & \multicolumn{8}{|c|}{ Padrão raiz } \\
\hline $0,0-0,2$ & 1,237 & 0,86 & 1,662 & 0,70 & 1,214 & 0,68 & 0,483 & 0,62 \\
\hline $0,2-0,4$ & 0,624 & 0,76 & 0,675 & 0,46 & 0,569 & 0,56 & 0,428 & 0,59 \\
\hline $0,4-0,6$ & 0,583 & 0,76 & 0,399 & 0,46 & 0,417 & 0,53 & 0,402 & 0,43 \\
\hline $0,6-0,8$ & 0,546 & 0,78 & 0,388 & 0,44 & 0,420 & 0,49 & 0,384 & 0,48 \\
\hline & \multicolumn{8}{|c|}{ Raízes } \\
\hline $0,0-0,2$ & 0,516 & 0,79 & 0,497 & 0,61 & 0,529 & 0,69 & 0,381 & 0,77 \\
\hline $0,2-0,4$ & 0,410 & 0,73 & 0,431 & 0,70 & 0,412 & 0,57 & 0,378 & 0,67 \\
\hline $0,4-0,6$ & 0,400 & 0,67 & 0,379 & 0,55 & 0,378 & 0,52 & 0,379 & 0,59 \\
\hline $0,6-0,8$ & 0,390 & 0,58 & 0,376 & 0,52 & 0,386 & 0,46 & 0,377 & 0,54 \\
\hline & \multicolumn{8}{|c|}{ Solo + resíduo de raízes } \\
\hline $0,0-0,2$ & 0,373 & 0,04 & 0,373 & 0,08 & 0,374 & 0,05 & 0,372 & 0,04 \\
\hline $0,2-0,4$ & 0,371 & 0,04 & 0,371 & 0,07 & 0,371 & 0,04 & 0,371 & 0,03 \\
\hline $0,4-0,6$ & 0,371 & 0,03 & 0,371 & 0,08 & 0,371 & 0,03 & 0,371 & 0,03 \\
\hline $0,6-0,8$ & 0,370 & 0,02 & 0,369 & 0,05 & 0,369 & 0,02 & 0,369 & 0,02 \\
\hline
\end{tabular}

(1)dac: dias após o corte. 
porcentagem de átomos de ${ }^{15} \mathrm{~N}$ no solo natural sem aplicação do traçador; $\%{ }^{15} \mathrm{~N}_{\text {raiz m.a. }}$ é a abundância em porcentagem de átomos de ${ }^{15} \mathrm{~N}$ na raiz metabolicamente ativa (padrão).

O N total das amostras (NTa) e a quantidade de $\mathrm{N}$ da amostra, proveniente de raízes metabolicamente ativas (QNaRMA), foram expressos pelas seguintes equações:

$\mathrm{Nta}=\mathrm{M}_{\text {amostra }} \times\left(\% \mathrm{~N}_{\text {amostra }} / 10^{2}\right)$

em que: $\mathrm{M}_{\mathrm{amostra}}$ é a massa da amostra; $\% \mathrm{~N}_{\text {amostra }}$ é o teor de $\mathrm{N}$ na amostra.

$\mathrm{QNaRMA}=\left(\% \mathrm{NaRMA} / 10^{2}\right) \times \mathrm{NTa}$

Por meio da QNaRMA, pode-se calcular a massa de matéria seca de raízes metabolicamente ativas da amostra (MSRMAa):

MSRMAa $=\left[(\mathrm{QNaRMA}) \times 10^{2}\right] / \% \mathrm{~N}_{\text {raiz m.a. }}$

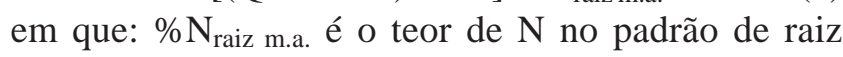
metabolicamente ativa.

Na inclusão de todas as variáveis utilizadas no cálculo da MSRMAa na equação (4), tem-se:

MSRMAa $=\left\{\left[\left(\%{ }^{15} \mathrm{~N}_{\text {exc. amostra }}\right) /\left(\%{ }^{15} \mathrm{~N}_{\text {exc. raiz m.a. }}\right)\right] \mathrm{x}\right.$ $\left.\mathrm{M}_{\text {amostra }} \mathrm{X} \% \mathrm{~N}_{\text {amostra }}\right\} / \% \mathrm{~N}_{\text {raiz m.a. }}$

em que: $\%{ }^{15} \mathrm{~N}_{\text {exc. amostra }}$ e $\%{ }^{15} \mathrm{~N}_{\text {exc. raiz m.a. }}$ são a porcentagem de átomos de ${ }^{15} \mathrm{~N}$ em excesso na amostra e na raiz metabolicamente ativa, respectivamente.

A equação (5) pode ser usada para amostras de solo, amostras de solo contendo resíduos de raízes ou amos- tras de raízes, desde que as massas das amostras sejam utilizadas em base seca.

A massa do sistema radicular, tanto de raízes totais como de raízes metabolicamente ativas, foi comparada, no perfil do solo, pelo teste de Tukey a 5\% de probabilidade.

\section{Resultados e Discussão}

Os resultados de porcentagem em átomos de ${ }^{15} \mathrm{~N}$ e de teor de $\mathrm{N}$ do padrão do solo natural, do padrão de raiz metabolicamente ativa, das amostras de raízes e do solo mais resíduos de raízes são apresentados na Tabela 1; os resultados da massa de raízes totais e metabolicamente ativas são apresentados na Tabela 2, ambos no perfil do solo e por época de amostragem.

Não houve diferença de massa do sistema radicular e de sua distribuição no perfil do solo depois da amostragem de janeiro, pelo fato de a cultura encontrarse no 8o mês de desenvolvimento e, também, por não ter havido um período de deficiência hídrica severa, o qual poderia ter causado morte de raízes nos meses precedentes às amostragens. A morte do sistema radicular da cana-de-açúcar ocorre, de acordo com Aguiar (1978) e Vasconcelos (2002), com a deficiência hídrica, independentemente da fase de desenvolvimento, sendo sua renovação dependente do fim do período de falta de água no solo.

Tabela 2. Massa de matéria seca $\left(\mathrm{g} \mathrm{dm}^{-3}\right.$ ) de raízes totais (RT) e de raízes metabolicamente ativas (RMA), por ponto de amostragem, nas quatro épocas de amostragem ${ }^{(1)}$.

\begin{tabular}{|c|c|c|c|c|c|c|c|c|c|}
\hline \multicolumn{2}{|c|}{ Ponto de amostragem } & \multicolumn{2}{|c|}{ Jan./256 dac } & \multicolumn{2}{|c|}{ Mar./307 dac } & \multicolumn{2}{|c|}{ Maio/369 dac } & \multicolumn{2}{|c|}{ Jun./411 dac } \\
\hline Prof. (m) & $\mathrm{DL}(\mathrm{m})$ & RT & RMA & RT & RMA & RT & RMA & RT & RMA \\
\hline \multirow[t]{3}{*}{$0,0-0,2$} & $\mathrm{Na}$ linha & $2,02 \mathrm{a}$ & $0,73 a$ & $2,59 \mathrm{a}$ & $0,60 \mathrm{a}$ & $3,24 \mathrm{a}$ & $1,96 a$ & $3,68 \mathrm{a}$ & $1,85 \mathrm{a}$ \\
\hline & $0,14-0,42$ & $0,65 \mathrm{ab}$ & $0,14 \mathrm{bc}$ & $1,06 \mathrm{~b}$ & $0,23 b$ & $0,68 b$ & $0,32 b$ & $0,61 b$ & $0,19 \mathrm{c}$ \\
\hline & $0,42-0,70$ & $0,32 b c$ & $0,06 \mathrm{c}$ & $0,95 b$ & $0,05 \mathrm{c}$ & $0,73 b$ & $0,09 \mathrm{c}$ & $0,32 b c$ & $0,20 \mathrm{c}$ \\
\hline Média & & $1,00 \mathrm{~B}$ & $0,31 \mathrm{C}$ & $1,53 \mathrm{~A}$ & $0,29 \mathrm{C}$ & $1,55 \mathrm{~A}$ & $0,79 \mathrm{~B}$ & $1,54 \mathrm{~A}$ & $0,75 \mathrm{~B}$ \\
\hline \multirow[t]{3}{*}{$0,2-0,4$} & $\mathrm{Na}$ linha & $0,42 b c$ & $0,25 \mathrm{~b}$ & $0,88 \mathrm{~b}$ & $0,50 \mathrm{a}$ & $0,59 \mathrm{bc}$ & $0,08 \mathrm{c}$ & $0,64 b$ & $0,58 \mathrm{~b}$ \\
\hline & $0,14-0,42$ & $0,16 \mathrm{c}$ & $0,09 \mathrm{c}$ & $0,29 \mathrm{c}$ & $0,08 \mathrm{c}$ & $0,19 \mathrm{~cd}$ & $0,16 \mathrm{bc}$ & $0,37 b c$ & $0,12 \mathrm{c}$ \\
\hline & $0,42-0,70$ & $0,11 \mathrm{c}$ & $0,09 \mathrm{c}$ & $0,18 \mathrm{c}$ & $0,15 \mathrm{bc}$ & $0,12 \mathrm{~cd}$ & $0,11 \mathrm{c}$ & $0,10 \mathrm{c}$ & $0,16 \mathrm{c}$ \\
\hline Média & & $0,23 \mathrm{D}$ & $0,14 \mathrm{D}$ & $0,45 \mathrm{C}$ & $0,24 \mathrm{D}$ & $0,30 \mathrm{C}$ & $0,12 \mathrm{D}$ & $0,37 \mathrm{C}$ & $0,27 \mathrm{CL}$ \\
\hline \multirow[t]{3}{*}{$0,4-0,6$} & $\mathrm{Na}$ linha & $0,13 \mathrm{c}$ & $0,04 \mathrm{c}$ & $0,14 \mathrm{c}$ & $0,17 b c$ & $0,12 \mathrm{~cd}$ & $0,11 \mathrm{c}$ & $0,24 b c$ & $0,25 \mathrm{bc}$ \\
\hline & $0,14-0,42$ & $0,04 \mathrm{c}$ & $0,05 \mathrm{c}$ & $0,06 \mathrm{c}$ & $0,08 \mathrm{c}$ & $0,02 \mathrm{~d}$ & $0,09 \mathrm{c}$ & $0,02 \mathrm{c}$ & $0,08 \mathrm{c}$ \\
\hline & $0,42-0,70$ & $0,05 \mathrm{c}$ & $0,06 \mathrm{c}$ & $0,04 \mathrm{c}$ & $0,14 \mathrm{c}$ & $0,04 \mathrm{~d}$ & $0,08 \mathrm{c}$ & $0,05 \mathrm{c}$ & $0,11 \mathrm{c}$ \\
\hline Média & & $0,07 \mathrm{D}$ & $0,05 \mathrm{D}$ & $0,08 \mathrm{D}$ & $0,13 \mathrm{D}$ & $0,06 \mathrm{D}$ & $0,09 \mathrm{D}$ & $0,10 \mathrm{D}$ & $0,15 \mathrm{D}$ \\
\hline \multirow[t]{3}{*}{$0,6-0,8$} & $\mathrm{Na}$ linha & $0,12 \mathrm{c}$ & $0,09 \mathrm{c}$ & $0,10 \mathrm{c}$ & $0,12 \mathrm{c}$ & $0,14 \mathrm{~cd}$ & $0,16 \mathrm{c}$ & $0,06 \mathrm{c}$ & $0,14 \mathrm{c}$ \\
\hline & $0,14-0,42$ & $0,07 \mathrm{c}$ & $0,06 \mathrm{c}$ & $0,09 \mathrm{c}$ & $0,14 \mathrm{c}$ & $0,07 \mathrm{~d}$ & $0,16 \mathrm{c}$ & $0,06 \mathrm{c}$ & $0,12 \mathrm{c}$ \\
\hline & $0,42-0,70$ & $0,06 \mathrm{c}$ & $0,08 \mathrm{c}$ & $0,03 \mathrm{c}$ & $0,04 \mathrm{c}$ & $0,07 \mathrm{~d}$ & $0,11 \mathrm{c}$ & $0,05 \mathrm{c}$ & $0,11 \mathrm{c}$ \\
\hline Média & & $0,08 \mathrm{D}$ & $0,08 \mathrm{D}$ & $0,07 \mathrm{D}$ & $0,10 \mathrm{D}$ & $0,09 \mathrm{D}$ & $0,14 \mathrm{D}$ & $0,06 \mathrm{D}$ & $0,12 \mathrm{D}$ \\
\hline Média geral & & $0,35 \mathrm{~B}$ & $0,14 \mathrm{C}$ & $0,53 \mathrm{~A}$ & $0,19 \mathrm{C}$ & $0,50 \mathrm{~A}$ & $0,29 \mathrm{C}$ & $0,52 \mathrm{~A}$ & $0,33 \mathrm{~B}$ \\
\hline
\end{tabular}

(1)Médias seguidas pela mesma letra não diferem entre si pelo teste de Tukey a 5\% de probabilidade, sendo que letras minúsculas comparam médias nas colunas, em cada época, e letras maiúsculas comparam médias nas linhas, entre épocas; dac: dias após o corte; prof.: profundidade; DL: distância da linha de plantio. 
Ao se comparar a massa de matéria seca de raízes metabolicamente ativas com a massa de matéria seca do total de raízes (Tabela 2), pode-se observar que, apesar de as raízes ativas aumentarem no decorrer do tempo, concomitantemente com as raízes totais, elas diferem entre si nas camadas do solo onde foi encontrado mais de $90 \%$ das raízes $(0,0-0,2 \mathrm{~m}$ e $0,2-0,4 \mathrm{~m}$ de profundidade). Por sua vez, nas raízes das profundidades de $0,4-0,6 \mathrm{~m}$ e $0,6-0,8 \mathrm{~m}$, nos meses de março, maio e junho, não se observou diferença, o que também foi verificado por Vasconcelos (2002) em profundidades similares.

A massa de raízes vivas aumentou significativamente da primeira até a última amostragem, passando de $0,31 \mathrm{~g} \mathrm{dm}^{-3}$ para $0,75 \mathrm{~g} \mathrm{dm}^{-3}$ nos $0,20 \mathrm{~m}$ superficiais (Tabela 2). Na média das profundidades $(0,0-0,8 \mathrm{~m})$, esse aumento foi maior, passando de $0,15 \mathrm{~g} \mathrm{dm}^{-3}$ para $0,33 \mathrm{~g} \mathrm{dm}^{-3}$, o que equivale aproximadamente ao triplo do valor inicial.

A porcentagem de raízes vivas em relação ao total de raízes, por profundidade de amostragem, aumentou com o tempo; $43 \%$ das raízes totais encontravam-se ativas em janeiro e, em junho, essa porcentagem foi de $64 \%$. Pode-se inferir que parte das raízes não se encontrava ativa, podendo essa fração do sistema radicular compreender tanto raízes mortas como raízes de cana-de-açúcar das linhas adjacentes não marcadas com o isótopo $\left({ }^{15} \mathrm{~N}\right)$, e que cresceram em direção à linha marcada. Poderiam, ainda, compreender raízes que estariam funcionando como órgão de reserva de nutrientes e energia e que não estariam recebendo compostos assimilados da parte aérea da planta.

Faroni (2004) observou tendência de maior marcação isotópica nas raízes mais superficiais ao solo e próximas à linha de cana-de-açúcar e atribuiu esse efeito à possível desuniformidade de translocação do ${ }^{15} \mathrm{~N}$ no sistema radicular, bem como à presença de raízes mortas ou raízes de plantas das linhas adjacentes, as quais não foram marcadas com ${ }^{15} \mathrm{~N}$ e apresentavam abundância natural.

Outro fato importante foi a maior distribuição porcentual de raízes vivas em profundidade, principalmente na camada de 0,4-0,8 $\mathrm{m}$, em média, maiores que $100 \%$ do total de raízes pela quantificação das raízes metabolicamente ativas do solo (depois do peneiramento), enquanto em superfície, a média foi de $38 \%$. Essa tendência de aumento de raízes metabolicamente ativas em profundidade também foi constatada por Aguiar (1978).

Na Tabela 3, está descrita a massa de raízes vivas que passou pela peneira, no processo de separação do solo, e deixou de ser contabilizada na massa de raízes metabolicamente ativas. Como as amostras coletadas passaram por peneira de malha de $2 \mathrm{~mm}$, muitas raízes finas e fragmentos de raízes permaneceram no solo. Rizodeposições e descamações radiculares também poderiam fazer parte desse material, mas, pela brevidade do período entre a aplicação da uréia e a colheita (96 horas), essa possibilidade pode ser considerada com restrições.

Quanto maior a massa de raízes de uma amostra, maior a quantidade de raízes perdidas no peneiramento. Em algumas profundidades, a massa residual de raízes metabolicamente ativas foi maior do que a separada pelo peneiramento, principalmente em amostras das maiores profundidades, demonstrando que raízes não ativas também devem ter passado pelo peneiramento e não foram contabilizadas, podendo ser os valores apresentados neste trabalho ligeiramente subestimados para a massa de matéria seca de raízes totais. O resíduo de raízes metabolicamente ativas no solo variou de 27 a $40 \%$ do total destas raízes. A quantificação dessas raízes é importante para determinar as raízes finas e fragmentos de raízes que são perdidos, no processo de separação

Tabela 3. Porcentagem de raízes metabolicamente ativas separadas do solo por peneiramento (RMAP) e resíduo de raízes metabolicamente ativas no solo (RMAS) em diferentes profundidades nas quatro épocas de amostragem.

\begin{tabular}{|c|c|c|c|c|c|c|c|c|}
\hline \multirow[t]{2}{*}{ Profundidade (m) } & \multicolumn{2}{|c|}{ Jan./256 dac ${ }^{(1)}$} & \multicolumn{2}{|c|}{ Mar./307 dac } & \multicolumn{2}{|c|}{ Maio/369 dac } & \multicolumn{2}{|c|}{ Jun./411 dac } \\
\hline & RMAP & RMAS & RMAP & RMAS & RMAP & RMAS & RMAP & RMAS \\
\hline $0,0-0,2$ & 81 & 19 & 77 & 23 & 85 & 15 & 85 & 15 \\
\hline $0,2-0,4$ & 55 & 45 & 76 & 24 & 51 & 49 & 66 & 34 \\
\hline $0,4-0,6$ & 16 & 84 & 37 & 63 & 28 & 72 & 55 & 45 \\
\hline $0,6-0,8$ & 16 & 84 & 42 & 58 & 31 & 69 & 37 & 63 \\
\hline Média & 60 & 40 & 66 & 34 & 70 & 30 & 73 & 27 \\
\hline
\end{tabular}

(1)dac: dias após o corte. 
do solo, que pelo método empregado puderam ser recuperadas.

Noordwijk \& Floris (1979), ao trabalhar com métodos de lavagem e armazenamento de raízes de trigo, observaram que, dependendo do método ou do conjunto de métodos utilizados para separar as raízes do solo e armazená-las até o processamento, podem ocorrer perdas de $9 \%$ a $43 \%$. Os autores verificaram, ainda, perda de $17 \%$ da massa de raízes totais, utilizando o mesmo método empregado neste experimento.

Dessa forma, raízes de pequeno diâmetro que permanecem no solo depois do peneiramento são relevantes em estudos de sistemas radiculares. Quanto menor o diâmetro da raiz, maior sua área específica e maior o contato com a solução do solo para a absorção de água e nutrientes. Nas raízes finas e radicelas ocorrem as infecções por micorrizas, que aumentam a área de absorção, além de elevar a disponibilidade de alguns nutrientes (Rheinheimer \& Anghinoni, 2001).

A maioria dos trabalhos que envolvem várias técnicas no estudo de raízes, principalmente de culturas perenes, não faz distinção entre raízes metabolicamente ativas e mortas, nem menção ao fluxo de emissão de novas raízes a cada ciclo da planta, o que é um contra-senso, já que raízes vivas são responsáveis pela relação solo-planta, principalmente na absorção de água e nutrientes.

Essa técnica pode ser usada em estudos com outras culturas, pois, além de permitir avaliar o crescimento e a renovação do sistema radicular, ela permite determinar os estoques de $\mathrm{N}$, principalmente em plantas que rebrotam à custa de reservas do sistema radicular depois do corte, como a cana-de-açúcar.

\section{Conclusão}

O método da diluição isotópica com ${ }^{15} \mathrm{~N}$ possibilita avaliar a massa de raízes metabolicamente ativas (vivas) de cana-de-açúcar e sua distribuição no solo, assim como quantificar a massa de raízes metabolicamente ativas que não são quantificadas no processo de peneiramento.

\section{Agradecimentos}

À Fapesp, pelo financiamento do trabalho; ao Grupo Cosan S/A, pela cessão da área experimental e apoio nas colheitas.

\section{Referências}

AGUIAR, S.F. Observações sobre sistema radicular de cana planta (Saccharum spp.). Jaboticabal: Faculdade de Ciências Agrária e Veterinárias, Universidade Estadual Paulista, 1978. 24p.

BACCHI, O.O.S. Botânica da cana-de-açúcar. In: ORLANDO FILHO, J. Nutrição e adubação da cana-de-açúcar no Brasil. Piracicaba: IAA/Planalsucar, 1983. p.24-37.

BARRIE, A.; PROSSER, S.J. Automated analysis of ligth-element stable isotopes by isotope ratio mass spectrometry. In: BOUTTON, T.W.; YAMSAHI, S. (Ed.). Mass spectrometry of soils. New York: Marcel Dekker, 1996. p.1-46.

BLACKBURN, F. Sugarcane. New York: Longman, 1984. 414p.

CAMARGO, P.B. Dinâmica do nitrogênio dos fertilizantes uréia $\left({ }^{15} \mathrm{~N}\right)$ e aquamônia $\left({ }^{15} \mathrm{~N}\right)$ incorporados ao solo na cultura de cana-de-açúcar. 1989. 104p. Dissertação (Mestrado) - Escola Superior de Agricultura Luiz de Queiroz, Piracicaba.

CASAGRANDE, A.A. Tópicos de morfologia e fisiologia da cana-de-açúcar. Jaboticabal: Funep, 1991. 157p.

EMBRAPA. Centro Nacional de Pesquisa de Solos (Rio de Janeiro, RJ). Sistema brasileiro de classificação de solos. Rio de Janeiro, 1999. 412p.

FARONI, C.E. Sistema radicular de cana-de-açúcar e identificação de raízes metabolicamente ativas. 2004. 68p. Dissertação (Mestrado) - Escola Superior de Agricultura Luiz de Queiroz, Piracicaba.

JANSEN, H.H.; BRUINSMA, Y. Methodology for the quantification of root and rhizosphere nitrogen dynamics by exposure of shoots to ${ }^{15} \mathrm{~N}$-labelled ammonia. Soil Biology and Biochemistry, v.21, p.189196, 1989.

KÖPKE, V. Methods for studying root growth. In: SYMPOSIUM ON THE SOIL/ROOT SYSTEM, 1980, Londrina. Proceedings. Londrina: Fundação Instituto Agronômico do Paraná, 1981. p.303318.

MALAVOLTA, E. Fertilizing for high yield sugarcane. Basel: IPI, 1994. 104p. (Bulletin, 14).

McNEILL, A.M.; ZHU, C.; FILLERY, R.P. Use of in situ ${ }^{15} \mathrm{~N}-$ labelling to estimate the total below-ground nitrogen of pasture legumes in intact soil-plant systems. Australian Journal of Agricultural Research, v.48, p.295-304, 1997.

NOORDWIJK, M. van; FLORIS, J. Loss of dry weight during washing and storage of root samples. Plant and Soil, v.53, p.239243, 1979

RHEINHEIMER, D.S.; ANGHINONI, I. Distribuição do fósforo inorgânico em sistemas de manejo de solo. Pesquisa Agropecuária Brasileira, v.36, p.151-160, 2001.

RUSSEL, C.A.; FILLERY, I.R.P. In situ ${ }^{15} \mathrm{~N}$ labelling of lupin belowground biomass. Australian Journal of Agricultural Research, v.47, p.1035-1046, 1996.

TRIVELIN, P.C.O.; CAMARGO, P.B.; LIBARDI, P.L.; MORAES, S.O.; LARA CABEZAS, W.A.R.; PALHARES, A.L. Dinâmica do N dos fertilizantes: uréia $\left({ }^{15} \mathrm{~N}\right)$ e aquamônia $\left({ }^{15} \mathrm{~N}\right)$ incorporados ao solo na cultura da cana-de-açúcar. Piracicaba: Fealq; Cena, 1988. 84p. 
TRIVELIN, P.C.O.; VITTI, A.C.; OLIVEIRA, M.W.; GAVA, G.J.C.; SARRIÉS, G.A. Utilização de nitrogênio e produtividade da canade-açúcar (cana-planta) em solo arenoso com incorporação de resíduos da cultura. Revista Brasileira de Ciência do Solo, v.26, p.636-646, 2002.

VASCONCELOS, A.C.M. Desenvolvimento do sistema radicular e da parte aérea de socas de cana-de-açúcar sob dois sistemas de colheita. 2002. 140p. Tese (Doutorado) - Universidade Estadual Paulista, Jaboticabal.

VASCONCELOS, A.C.M.; CASAGRANDE, A.A.; PERECIN, D.; JORGE, L.A.C.; LANDELL, M.G.A. Avaliação do sistema radicular de cana-de-açúcar por diferentes métodos. Revista Brasileira de Ciência do Solo, v.27, p.849-858, 2003.

Recebido em 29 de julho de 2005 e aprovado em 31 de janeiro de 2006 